\title{
ACTIVIDAD ANTIFUNGICA DE QUITOSANO CARBA- MATO DE ETILO EN Candida albicans
}

\section{(Antifungal activity of chitosano ethil carbamate on Candida albicans)}

\author{
Eduardo Valenzuela $F^{1}$., \\ Carolina Maldonado S ${ }^{\mathbf{1}}$. \& Juan C. Paredes $\mathbf{G}^{\mathbf{2}}$. \\ ${ }^{1}$ Instituto de Microbiología e ${ }^{2}$ Instituto de Química, Facultad de Ciencias \\ Universidad Austral de Chile. Casilla 167, Valdivia. Chile.
}

Palabras clave: antifúngico, Candida, Quitosano Carbamato de etilo.

Key word: antifungal, Candida, chitosano ethil carbamate.

\section{RESUMEN}

El incremento de las infecciones producidas en seres humanos y/o animales por hongos y el aumento de la resistencia de estos últimos a algunos fármacos, han conducido a la búsqueda de nuevos productos con actividad antifúngica.

Producto de la síntesis química se ha obtenido la sustancia de origen natural, llamada Quitosano Carbamato de etilo (QCE) que ha demostrado acción antifúngica, particularmente a Candida albicans. Los objetivos de este trabajo fueron determinar "in vitro" la Concentración Minima Inhibitoria (CIM), Concentración Letal Media (CLM) y Letal (CL) de QCE para cultivos de C. albicans en CM al 2\%. Establecer para esta misma levadura su curva de crecimiento, el tiempo de inicio de acción del QCE y los cambios morfoló-gicos de las células levaduriformes en CM al 2\% con adición de QCE $(0.89 \mathrm{mg} / \mathrm{mL})$. Además, determinar la acción del QCE $(0.89 \mathrm{mg} / \mathrm{mL})$ para las levaduras Criptococcus albus, Saccharomyces cerevisiae, Sporobolomyces roseus y 5 cepas de C. albicans aisladas de casos clínicos en el Hospital Clínico Regional Valdivia (H.C.R.V.).

La CIMfue $0.25 \mathrm{mg} / \mathrm{mL}$, la CLMfue $0.45 \mathrm{mg} / \mathrm{mL}$ y la CL 0,89 mg/mL. La curva de crecimiento elaborada para los cultivos de C. albicans sin adición de QCE fue la típica de una levadura y, por el contrario, la elaborada para los cultivos adicionados con QCE sólo registró la etapa de latencia. El tiempo de inicio de la acción del QCE para la cepa control de $\boldsymbol{C}$. albicans comienza a las 12 horas de incubación. Las células de C. albicans obtenidas de cultivos tratados con QCE se mostraron colapsadas, de menor tamaño, no forman tubo germinativo y tampoco pseudomicelio. El QCE inhibió el desarrollo de cultivos de $\boldsymbol{C}$. albus, $\boldsymbol{S}$. cerevisiae, $\boldsymbol{S}$. roseus y para tres de cinco cepas ensayadas de $\boldsymbol{C}$. albicans obtenidas desde casos clínicos.

\section{ABSTRACT}

The increase of infections caused to man and/or animals by fungi and the higher resistance of the latter to some medicines have forced to look for new products having antifungal activity. After a chemical analysis, a natural substance called Chitosano Ethil Carbamate(CHEC)has shown to bear antifungal pro-perties mainly on Candida albicans. The objectives of this work were to determine "in vitro" the minimum inhi-bitory concentration(MIC), the lethal average concen-tration (LAC) and the lethal concentration (LC) of CHEC on cultures of C.albicans in 2\%CM. To establish for this same yeast its growth curve, the time of starting action of the CHEC and the morphological changes of yeast-like cells in 2\%CM having CHEC $(0.89 \mathrm{mg} 7 \mathrm{~mL})$ addition. Besides, to determine the CHEC (0.89mg $7 \mathrm{~mL}$ ) action on the yeasts Criptococcus albus, Saccharomyces cere-visiae, Sporobolomyces roseus and 5 C.albicans strains isolated from clinical cases at the Hospital Clinico Regional Valdivia (H.C.R.V.).The MIC was $0.25 \mathrm{mg} / \mathrm{mL}$, the LAC was $0.45 \mathrm{mg} / \mathrm{mL}$ and the $L C$ was $0.89 \mathrm{mg} / \mathrm{mL}$. The growth curve designed for C.albicans cultures without CHEC addition was similar to that of a yeast and,on the contrary, the one intended for cultures with CHEC added showed only the latency stage. The time of starting action of the CHEC for the controlling strain of C.albicans begins after 12hour-incubation. C.albicans cells resulting from CHEC treated cultures looked collapsed, smaller in size and with absence of germinative tube and pseudomycelia. The CHEC inhi-bited the development of C.albus, S.cerevisiae, S.roseus and of 3 out of 5 C.albicans assayed strains obtained from clinical cases.

\section{INTRODUCCION}

Candida albicans forma parte de la microbiota normal humana del tracto gastrointestinal, urinario, genital femenino y es considerado un patógeno oportunista de enfermedades denominadas “candidosis". Alvarado (2000), 
señala que otras levaduras capaces de producir micosis son Blastomyces dermatidis, Cryptococcus neoformans e Histoplasma capsulatum. Las levaduras presentan una membrana citoplasmática, rica en esteroles, que según Mandell et al. (1997), es el principal sitio afectado por la mayoría de los antifúngicos o antimicó-ticos, externa a la membrana presentan una pared celular constituida por manana y quitina, que también es afectada por antifúngicos. Zaias (1975), indica que $\boldsymbol{C}$. albicans es el principal agente causal de enfermedades fúngicas (candidosis oral, vaginal, cutáneas y en uñas) que se presentan generalmente en individuos inmunodeprimidos o sometidos a tratamientos extensos con antibióticos, aunque la mayoría de las infecciones producidas por $\boldsymbol{C}$. albicans son de origen endógeno, es posible la trans-misión interhumana (de la madre vía vaginal al hijo) y también puede adquirirse en ambientes hospitalarios. Zaror \& Gallardo (1989), señalan que las candidosis más frecuentes que se detectan en pacientes de la X Región de Chile son de tipo vaginal y en uñas. Bennett, citado en Mandell et al. (1997), indica que el agente primario para el tratamiento de las candidosis mucosas y cutáneas es la nistatina o clotrimazol vía tópica, para las candidosis del sistema digestivo ketoconazol y para las diseminadas la anfotericina $\mathrm{B}$, aunque últimamente se ha demostrado que fluconazol es una buena alternativa por sus vías de administración y la relativa carencia de toxicidad.

Si bien para tratar las patologías que causan las levaduras existen antifúngicos, algunos de ellos presentan serias desventajas al actuar sólo como fungistáticos o causar daños colaterales, pero lo más importante según Domínguez (1999), es que a nivel mundial se ha detectado un aumento de las levaduras resistentes a las drogas clásicas y tratamientos tradicionales con antifúngicos. Alvarado (2000), indica que este fenómeno se ha observado en cepas de $\boldsymbol{C}$. albicans aisladas de pacientes hospitalizados, donde generalmente los tratamientos con antimicóticos como por ejemplo ketoconazol o itraconazol son realizados por períodos prolongados de tiempo, señalándose que los microorganismos resistentes, surgen por la mutación de una cepa previamente sensibles. Por su parte, Hernández et al. (1997), indican que se ha demostrado que cepas de C. albicans aisladas de pacientes sometidos a terapias con fluconazol de larga duración, tienen niveles elevados de proteínas transportadoras (MFS) (ABC) que provocan la salida del fármaco, reduciendo así su acumulación intracelular.

Como resultado muchos antibióticos han perdido su eficacia y algunos ya no son útiles para tratar determinadas infecciones fúngicas.

Frente a la desventaja de algunos antifúngicos como son su modo de acción, los daños colaterales que producen algunos productos, al incremento de cepas le- vaduriformes resistentes a los antifúngicos tradicionales y al creciente interés por el estudio de las infecciones producidas por hongos levaduriformes y su combate, Vanden (1997), indica que básicamente se han barajado dos posibilidades, buscar en fuentes naturales (vegetales, microorganismos, etc.) nuevos productos con actividad antifúngica o realizar una síntesis química de ellos. Es así, que a partir de una molécula de origen natural, el quitosano, (1-4) 2 amino 2 deoxi Dglucopiranosa, se sintetizó el compuesto quitosano carbamato de etilo, el cual en ensayos previos mostró actividad antifúngica para $\boldsymbol{C}$. albicans. El quitosano es un biopolímero derivado de la desacetilación de la quitina, esta última molécula forma parte del exoesqueleto de crustáceos e insectos y de la pared celular de muchos hongos (Cárdenas et al. 2002), por su parte, los carbamatos son componentes de gran parte de los plaguicidas e insecticidas en actual uso.

En base a lo expuesto se planteo determinar "in vitro" en cultivos de $\boldsymbol{C}$. albicans la actividad antifúngica del quitosano carbamato de etilo, su concentración mínima inhibitoria (CIM), letal media (CLM), letal (CL), el tiempo de acción y los posibles cambios morfológicos en células de $\boldsymbol{C}$. albicans, además, determinar el espectro de acción en cepas de esta misma levadura y otras saprófitas.

\section{MATERIALES Y METODOS}

Se utilizó una cepa control del hongo levaduriforme Candida albicans proveniente del cepario CBS, Baarn Holanda. Además, 5 cepas de $\boldsymbol{C}$. albicans aisladas desde casos clínicos de pacientes del Hospital Clínico Regional Valdivia (H.C.R.V.) Chile y una cepa de cada una de las siguientes levaduras Criptococcus albus, Saccharomyces cerevisiae y Sporobolomyces roseus, del cepario del Instituto de Microbiología de la Facultad de Ciencias de la Universidad Austral de Chile.

1. Determinación in vitro de la Concentración Inhibitoria Mínima (CIM), Concentración Letal Media (CLM) y Concentración Letal (CL) de quitosano carbamato de etilo (QCE) en cultivos de $C$. albicans: desde un cultivo fresco de la cepa se realizaron diluciones seriadas, hasta la dilución $10^{7}$, luego alícuotas de $1 \mathrm{~mL}$ de la dilución respectiva y por triplicado se sembraron en tubos que contenían $5 \mathrm{~mL}$ de caldo malta al 2\% (CM 2 \%) sin y con adición de $1 \mathrm{~mL}$ de QCE a diferentes concentraciones $(0.25,0.30,0.40,0.45,0.60,0.85,0.89,0.90$, 1.0 y $1.5 \mathrm{mg} / \mathrm{mL}$ ). Sembrados los tubos se incubaron a $37^{\circ} \mathrm{C}$ por $24 \mathrm{~h}$., tras este período, de cada tubo en forma individual y por triplicado se extrajeron alícuotas $0.1 \mathrm{~mL}$ que se sembraron en placas Petrí que contenían $15 \mathrm{~mL}$ de agar extracto malta al 2\% (AEM al 2\%). Las placas se incubaron a $37^{\circ} \mathrm{C}$ por $24 \mathrm{~h}$. y luego se realizó a ojo desnudo 
alícuotas $0.1 \mathrm{~mL}$ que se sembraron en placas Petrí que contenían $15 \mathrm{~mL}$ de agar extracto malta al $2 \%$ (AEM al $2 \%$ ). Las placas se incubaron a $37^{\circ} \mathrm{C}$ por $24 \mathrm{~h}$. y luego se realizó a ojo desnudo el recuento de las colonias. Los resultados se expresaron como unidades formadoras de colonias/ $\mathrm{mL}(\mathrm{UFC} / \mathrm{mL}$ ). De igual manera se procedió con los productos controles clotrimazol $(0.016$ y 0.078 $\mathrm{mg} / \mathrm{mL})$ y griseofulvina $(0.03$ y $25 \mathrm{mg} / \mathrm{mL})$.

2. Curva de crecimiento y determinación del tiempo de acción del producto quitosano carbamato de etilo en cultivo de $C$. albicans.

Se recurrió a dos métodos de uso frecuente que se complementan:

a) análisis poblacional por cambios de turbidez del cultivo: $100 \mathrm{~mL}$ de $\mathrm{CM}$ al $2 \%$ estéril contenidos en un matraz se sembraron con una población levaduriforme inicial de $1.2 \times 10^{5} \mathrm{UFC} / \mathrm{mL}$ ( tiempo cero). A continuación el matraz se mantuvo en agitación constante a 1.5000 $\mathrm{rpm}, 23^{\circ} \mathrm{C}$ por $24 \mathrm{~h}$ en un agitador orbital Lab Line. Para realizar la Absorbancia $\left(\mathrm{A}^{\circ}\right)$ cada dos horas se extrajeron en forma estéril alícuotas de $1 \mathrm{~mL}$ que se depositaron en cubetas de vidrio y se leyeron a $560 \mathrm{~nm}$ versus el blanco (CM estéril) en un espectrofotómetro

- Ethican UV serie 500 , los datos obtenidos $\mathrm{A}^{\circ}$ versus tiempo se graficaron.

b) Análisis de crecimiento poblacional por recuento viable: cada dos horas se extrajo $1 \mathrm{~mL}$ del cultivo indicado en «a» y se depositó en un tubo que contenga 9 $\mathrm{mL}$ de agua destilada estéril, a partir de este tubo se realizaran diluciones seriadas, de estas se tomaron en forma independiente alícuotas de $0,1 \mathrm{~mL}$ y se sembraron por triplicado en placas Petri que contenían $15 \mathrm{~mL}$ de AEM al $2 \%$. Las placas se incubaron a $37^{\circ} \mathrm{C}$ por 24 $\mathrm{h}$, al término de este período se realizó el recuento de las colonias. Los títulos obtenidos se expresaron como $\mathrm{UFC} / \mathrm{mL}$ y luego se graficaron en función del tiempo.

Para determinar a que período de incubación el producto QCE comienza a ejercer su acción sobre $\boldsymbol{C}$. albicans, se procedió como se indicó anteriormente, con la salvedad que al matraz que contenía el medio de cultivo se le adicionaron $0.89 \mathrm{mg}$ de QCE. $/ \mathrm{mL}$.

3. Determinación de la acción de quitosano carbamato de etilo (QCE) en cepas de $C$. albicans y algunas especies de levaduras saprófitas: la determinación de la acción de QCE fue ensayada en 5 cepas clínicas de esta levadura y 1 cepa de cada una de las siguientes especies Criptococcus albus, Saccharomyces cerevisiae y Sporobolomyces roseus, el ensayo se realizó igual como se indica en el punto 1 , a excepción de la concentración de QCE que fue de $0.89 \mathrm{mg} / \mathrm{mL}$.

4. Determinación de cambios morfológicos de $C$. albicans mediante microscopía óptica: tubos que contenían $5 \mathrm{~mL}$ de CM $2 \%$ sin y con adición de $1 \mathrm{~mL}$ de QCE $(0,80 \mathrm{mg} / \mathrm{mL})$, fueron sembrados con dos inóculos (del tamaño de la argolla de un asa de siembra) de un cultivo fresco de la cepa control de $C$. albicans. Los tubos se incubaron a $37^{\circ} \mathrm{C}$ por 24 horas. Luego los tubos fueron centrifugado por $30 \mathrm{~min}$ a $300 \mathrm{rpm}$ en una centrífuga Sorvell RT $6000 \mathrm{~s}$, con el precipitado se realizaron preparaciones en fresco, utilizando como líquido de montaje agua. Las preparaciones fueron observadas en un microscopio fotónico Carl Zeiss.

\section{RESULTADOS Y DISCUSION}

En la Tabla 1, se indican la Concentración Inhibitoria Mínima (CIM), y Concentración Letal (CL) de quitosano carbamato de etilo y otros antifúngicos de uso corriente determinadas in vitro para inhibir o matar la poblaciones de $\boldsymbol{C}$. albicans. Valenzuela \& Paredes (datos no publicados) en estudios previos determinaron que al agregar gotas de quitosano carbamato de etilo

Tabla 1. Inhibición del crecimiento de $C$. albicans por antifúngicos.

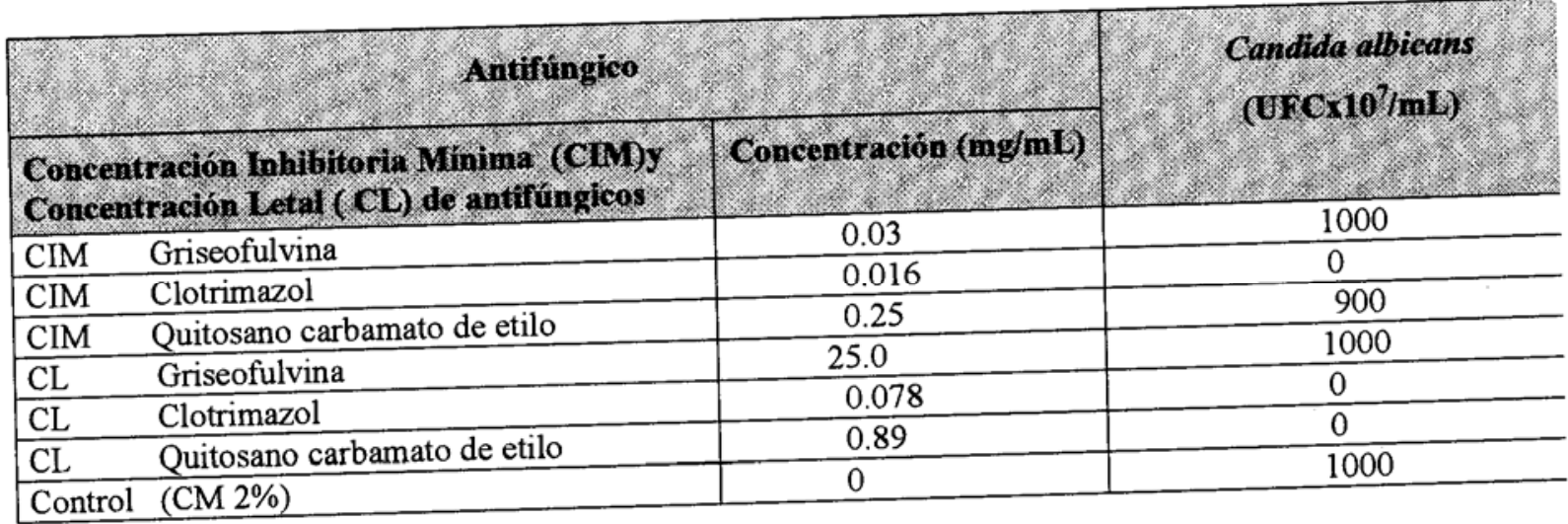


(QCE) sobre cultivos de $C$. albicans que se desarrollaban en AEM al $2 \%$ se formaban halos inhibitorios. En base a este antecedente, en un primer ensayo del presente estudio se planteó determinar la CIM, CLM y CL de QCE para cultivos de C. albicans. Como se muestra en la Tabla 1, la CIM de QCE para los cultivos de $C$. albicans es de $0.25 \mathrm{mg} / \mathrm{mL}$, la CLM es $0.45 \mathrm{mg} / \mathrm{mL}$ y CL es de $0.89 \mathrm{mg} / \mathrm{mL}$, al comparar estos resultados con los obtenidos para los antifúngico controles utilizados a la concentraciones indicadas por De Sousa (1991) y Pulgar (2000), la CIM y CL para los cultivos de C. albicans tratados con griseofulvina fueron negativas y para los tratados con clotrimazol son CIM $0.016 \mathrm{mg} / \mathrm{mL}$ (Plempel et $a l, 1974)$ y CL $0.078 \mathrm{mg} / \mathrm{mL}$ (Iwata \& Yamaguchi, 1975). Para el caso de los cultivos de $C$. albicans tratados con griseofulvina estos resultados coinciden con los señalados por Pulgar (2000), pues este antifúngico tiene solo acción sobre hongos no dermatofitos. Por su parte, al comparar la CIM $(0.25 \mathrm{mg} / \mathrm{mL})$ y $\mathrm{CL}(0.89 \mathrm{mg} / \mathrm{mL})$ obtenida para QCE versus la CIM $(0.016 \mathrm{mg} / \mathrm{mL})$ y CL $(0.078 \mathrm{mg} / \mathrm{mL})$ para clotrimazol, queda establecido que las concentraciones para este último antifúngico son mucho menores que las determinadas para $\mathrm{QCE}$, esto puede atribuirse al mecanismo de acción del clotrimazol, que actúa a nivel de la formación de la pared del hongo (Iwata \& Yamaguchi, 1975). Por otra parte, los resultados antes señalados para QCE dejan en evidencia que esta molécula presenta actividad antifúngica para $C$. albicans. En estudios realizados por Bell et al. (1998), se hace referencia del uso de quitosano puro y en mezcla con quitina para el tratamiento contra hongos, estos autores determinaron una disminución del desarrollo in vitro de Fusarium spp. y Penicillium spp. al ser tratados con 3 $\mathrm{mg} / \mathrm{mL}$ de quitosano. Cárdenas et al. (2002), indican el empleo de derivados de quitosano, como metil y etil carbamato en agricultura, pues sus actividades naturales como fungicidas, insecticidas y plaguicidas se conocen, por ej. como acaricidas se usan concentraciones de 0.023 $\mathrm{mg} / \mathrm{mL}$ y como plaguicidas entre $8.1 \times 10^{-6}-18 \times 10^{-5} \mathrm{mg} /$ $\mathrm{mL}$.

En el presente estudio, en un segundo ensayo se determino el crecimiento poblacional de $C$. albicans en CM. $2 \%$, adicionado y no adicionado de QCE $(0.89 \mathrm{mg} /$ $\mathrm{mL}$ ), mediante la lectura de $\mathrm{A}^{\circ}$ y el recuento de las células viables. Las curvas de crecimiento se muestran en la Figura 1.

Como se observa en la Figura 1, tanto los cultivos de $C$. albicans adicionados y no adicionados con QCE registraron igual crecimiento hasta las 12 horas de incubación, una $\mathrm{A}^{\circ}$ de $0.300 \mathrm{~nm}, \mathrm{y}$ un crecimiento poblacional de $5.0 \times 10^{4}\left(\log _{C}=4,7\right)$, pero a partir de las 14 horas de incubación en los cultivos adicionados con QCE se determinó una clara disminución del crecimiento, una $\mathrm{A}^{\circ}$ promedio de $0.458 \mathrm{~nm}$. y un crecimiento promedio de $4.0 \times 10^{1} \mathrm{UFC} / \mathrm{mL}\left(\log _{\mathrm{C}}=1,6\right)$, muy similar al del tiempo cero donde fue $2.5 \times 10^{1} \mathrm{UFC} / \mathrm{mL}\left(\log _{\mathrm{c}}=\right.$ 1,4). Por su parte, los cultivos de C. albicans sin adición de QCE después de las 12 horas de incubación, comienzan la etapa de crecimiento exponenciál, que se prolonga hasta las 22 horas de incubación. Por lo tanto, el QCE

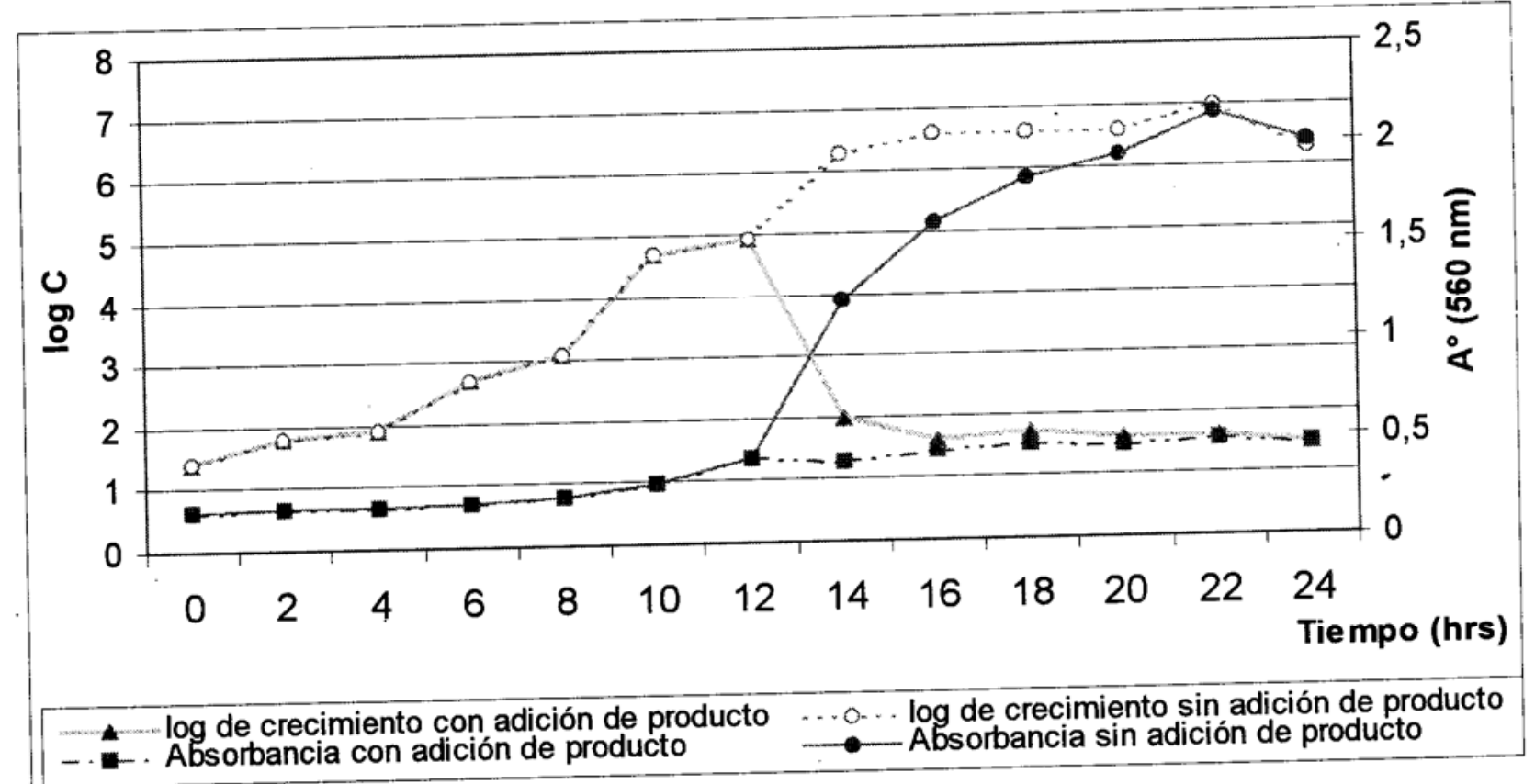

Figura 1.- Curvas de crecimiento de C.albicans en $\mathrm{CM}$ al $2 \%$ con y sin adición de QCE. 
ejercería su efecto "in vitro" en los cultivos de $\boldsymbol{C}$. albicans luego de las 12 horas de incubación. Cook (1958), señala que el tiempo generacional promedio de los hongos levaduriformes es de 6 horas aproximadamente, lo que indicaria que en los cultivos de $C$. albicans adicionados con QCE, este producto debería haber sido absorbido por las células levaduriformes y luego ejercer su acción. Según Cárdenas et al. (2002), el peso molecular 3200 D y forma estructural (compleja) del QCM no serían impedimento para ingresar a la célula levaduriforme. Plempel et al. (1974), señalan la acción del clotrimazol sobre cepas de $\boldsymbol{C}$. albicans "in vitro" en la fase de pseudomicelio a nivel de la formación de la pared celular. Por otro lado Cutsem et al. (1981), indican que luego de las 4 horas de cultivo, las células de C. albicans no presentan elongación del tubo germinativo, al ser tratadas "in vitro" con ketoconazol, Biasoli et al. (2000), finalmente indican que fluconazol ejerce su acción "in vitro" en cultivos de $\boldsymbol{C}$. albicans luego de transcurridas 2 horas de incubación, en un $20 \%$ de las levaduras, mientras que en el $80 \%$ restante, siguen su crecimiento emitiendo el tubo germinativo.

Los datos expuestos dejan en evidencia que el QCE requiere para su inicio de acción in vitro un período más prolongado (12 horas) en comparación con otros antifúngicos (2 a 4 horas) ensayados contra $C$. albicans, además se podría especular que este producto debería acumularse en el interior de las células y luego ejercer su acción.

En un tercer ensayo del presente estudio cuyos resultados se presentan en la Tabla 2, se determinó la acción del QCE a la concentración de la CL $(0.89 \mathrm{mg} / \mathrm{mL})$ en cultivos de distintas cepas de $\boldsymbol{C}$. albicans aisladas desde casos clínicos y cultivos de las levaduras saprófitas pertenecientes a las especies Criptococcus albus, Saccharomyces cereviciae y Sporobolomyces roseus. En un último ensayo se determinaron los cambios morfológicos de células de $\boldsymbol{C}$. albicans cultivadas en $\mathrm{CM}$ al $2 \%$ adicionado de quitosano carbamato $(0.80 \mathrm{mg} / \mathrm{mL})$.

Como se muestra en la Tabla 3, tras el ensayo con QCE no hubo desarrollo de los cultivos de las levaduras saprófitas y también de 3 de las 5 cepas de $\boldsymbol{C}$. albicans aisladas desde casos clínicos. Las levaduras saprófitas ensayadas y $\boldsymbol{C}$. albicans pertenecen a grupos taxonómicos distintos y no guardan una estrecha relación filogenética, así, $\boldsymbol{S}$. cereviciae taxonómicamente pertenece a la División Ascomycota. S. roseus presenta una estrechamente relacionado con los hongos de la División Basidiomycota, por su parte $C$. albicans y $C$. albus son tratados taxonómicamente como hongos mitosporicos. Estos antecedentes permiten especular que el QCE debería tener acción, ya sea, sobre estructuras celulares (ej. membrana citoplásmatica), organelos (ej. ribosomas)
Tabla 2. Determinación de la inhibición del crecimiento de diferentes cepas de Candida albicans aisladas desde casos clínicos y levaduras saprófitas tratadas con quitosano carbamato de etilo

\begin{tabular}{|l|c|}
\hline \multicolumn{1}{|c|}{ Taxa levaduriforme } & $\begin{array}{c}\text { Quitosano } \\
\text { carbamato etilo } \\
(0.89 \mathrm{mg} \text { M) })\end{array}$ \\
\hline $\begin{array}{l}\text { Candida albicans } \\
\text { Caso clínico 1 }\end{array}$ & - \\
\hline $\begin{array}{l}\text { Candida albicans } \\
\text { Caso clínico 2 }\end{array}$ & - \\
\hline $\begin{array}{l}\text { Candida albicans } \\
\text { Caso clínico 3 }\end{array}$ & - \\
\hline $\begin{array}{l}\text { Candida albicans } \\
\text { Caso clínico } 4\end{array}$ & + \\
\hline $\begin{array}{l}\text { Candida albicans } \\
\text { Caso clínico 5 }\end{array}$ & + \\
\hline Cryptococcus albus & + \\
\hline $\begin{array}{l}\text { Saccharomyces } \\
\text { cerevisiae }\end{array}$ & - \\
\hline Sporobolomyces roseus & - \\
\hline
\end{tabular}

+se observa desarrollo. - no se observa desarrollo

constituyentes moleculares (ej. ergosterol) o vías metabólicas (ej. FDP) comunes de estas levaduras, y no a nivel de pared celular, pues quimicamente la pared celular de $\boldsymbol{S}$. cereviciae es diferente a la de $\boldsymbol{S}$. roseus y la de estas dos especies de la de $\boldsymbol{C}$. albicans y $\boldsymbol{C}$. albus. Esta proposición, en parte esta avalada por los cambios de las células de $\boldsymbol{C}$. albicans observados a microscopía. Las células de $C$. albicans cultivadas en $\mathrm{CM}$ al $2 \%$ sin adición de CQE son esféricas a ovaladas ( $5-6 \mu \mathrm{m}$ de diám), algunas células se observaron gemando, otras han formado tubo germinativo y un rudimentario pseudomicelio. por su parte, las células de $\boldsymbol{C}$. albicans cultivadas en presencia de QCE , se aprecian de menor tamaño $(2-3 \mu \mathrm{m}$ de diám) no presentan gemación y algunas se muestran colapsadas, pero no rotas, posiblemente debido a la salida de material citoplasmático. Además, se observó que estas células no producen tubo germinativo y pseudomicelio, lo que se podría deber a que alguna de las vías metabólicas no están operativas o algunos metabolitos esenciales no están siendo sintetizados para formar el pseudomicelio. Estas especulaciones dejan abiertas futuras líneas de investigación para dilucidar el o los mecanismo de acción del QCE. En lo que respecta a las cepas de $C$. albicans de casos clínicos que no fueron sensibles al QCE (casos 4 y 5) pueden deberse a algún tipo de resistencia generado por el tratamiento prolongado de los pacientes con antimicóticos. Según Vanden (1997), 
cos, así, tenemos la resistencia intrínseca definida como la ausencia de sensibilidad de una determinada especie de hongo hacia un determinado antifúngico; resistencia primaria aquella que presentan determinadas cepas de una especie de hongo a un antifúngico de forma natural (sin exposición previa) y la resistencia secundaria, aquella que es adquirida por el hongo como resultado del contacto con la sustancia antifúngica o similares. Las cepas de $\boldsymbol{C}$. albicans que no fueron sensibles al QCE se ceñirían al tipo de resistencia secundaria, pues las muestras de levaduras fueron obtenidas de pacientes sometidos a tratamientos con antifúngicos, puede que el producto utilizado en la terapia de estos paciente no sea estructuralmente igual al QCE, pero que actúe al mismo nivel del QCE, haciendo que las células de $\boldsymbol{C}$. albicans se encuentren desensi-bilizadas. Para comprender esta desensibilización, se deben conocer los mecanismos bioquímicos implicados en el desarrollo de resistencia a los antifúngicos, estos incluyen alteraciones de la membrana celular, defectos enzimáticos, aumento de la síntesis de metabolitos que compiten con el antifúngico y la alteraciones en las estructuras dianas. La base genética de la resistencia, radica sobre todo en mutaciones cromosómicas concretas, así por ejemplo Vanden (1997), señala que la resistencia a los azólicos puede relacionarse con una menor acumulación intracelular de ellos, esto puede deberse a una entrada reducida o a un aumento en la eliminación de los azólicos por parte de las células microbianas.

\section{REFERENCIAS}

Alvarado, D. (2000). Determinación del perfil de sensibilidad in vitro frenChitin y Chitosan on the incidence y severety of Fusarium Yellows of celery. Plant. Dis. 82: 322-328

Biasoli, M.; Tosello, M. \& Magaró, H. (2000). Efecto de la filamentización y el fluconazol sobre la adherencia de Candida albicans. Bol. Micol. 15: 49-56

Cárdenas, G.; Paredes, J.; Cabrera, G.; Casals, P. (2002). Synthesis and characterization of chitosan alkyl carbamates. Journ. Appli. Polymer science. 86: 2742-2747

Cook, H. (1958). The chemestry and biology of yeats. Edited by Academic Press inc, publishers, New York. USA.

Cutsem, J.; Borgers, M. \& Brabander, M. (1981). The activity of Ketoconazole on clinical isolates of Candida albicans cultured in a Mycelium promoting medium. Bol. Myk. 24: 596-602

De Sousa, M. (1991). Comportamiento de dermatófitos "in vitro" frente a griseofulvina y derivados imidazólicos. Tesis de doctorado en Micologia Universidad de Sao Paulo.

Domínguez, J. (1999). Comparación de medios de cultivo para el aislamiento e identificación de dermatofitos. Tesis de Tecnología Medica.

\section{CONCLUSIONES}

El producto quitosano carbamato de etilo (QCE) tiene actividad antifúngica in vitro para la cepa control de $\boldsymbol{C}$. albicans ensayada, pero la CIM y $\mathrm{CL}$ al igual que el tiempo de inicio de la acción (12 horas) son mayores a las descritas en la literatura para productos antifúngicos actualmente utilizados.

El QCE a la CL demostró ser eficaz para las levaduras Cryptococcus albus, Saccharomyces cerevisiae y Sporoboromyces roseus y para tres de cinco cepas ensayadas de $\boldsymbol{C}$. albicans obtenidas desde casos clínicos. Las células de $\boldsymbol{C}$. albicans provenientes de cultivos tratados con QCE in vitro presentaron un menor tamaño, se muestran colapsadas, no producen tubo germinativo y pseudomicelio en comparación a células de $\boldsymbol{C}$. albicans obtenidas de cultivos sin adición de QCE.

\section{AGRADECIMIENTOS}

Al proyecto DID-UACH S 200013 por financiar parte del presente estudio.

Escuela de Tecnología Médica, Facultad de Medicina, Universidad de Austral de Chile.

Hernández, M.; Pla, J. \& Nombela, C. (1997). Aspectos Moleculares y genéticos de la resistencia a azoles en Candida albicans. Rev. Iberoam. Micol. 14: 150-154

Iwata, K. \& Yamaguchi, H. (1975). Un antimicótico de amplio espectro canestèn, experiencias y perspectivas. Rev. Bayer AG, 1: 6-10

Mandell, G.; Bennett, J. \& Dolin, R. (1997). Enfermedades infecciosas principios y prácticas. Editorial Panamericana, Buenos Aires, Argentina.

Plempel, M.; Büchel, K.; Bartman, K.; Regel, E. (1974). Antimycotic properties of clotrimazole. Post. Medic. Journ. $1: 1-2$

Pulgar, R. (2000). Efecto de la griseofulvina sobre intestino de ratones. 